\title{
La gestión de los recursos faunísticos durante el Neolítico en la Sierra de Atapuerca (Burgos): los niveles 19 y 20 de la Cueva del Mirador
}

\author{
The exploitation of faunal resources in the Neolithic of the Sierra de Atapuerca (Burgos): \\ levels 19 and 20 of the Cueva del Mirador
}

\author{
Patricia Martín (*) \\ Jordi Rosell (*) \\ Josep María Vergès $(*)$
}

\section{RESUMEN}

En este trabajo se presentan los datos obtenidos a partir del análisis zooarqueológico y tafonómico de los restos faunísticos recuperados en los niveles 19 y 20 de la Cueva del Mirador (Sierra de Atapuerca, Burgos). El objetivo fundamental ha sido obtener información sobre la gestión de los recursos faunísticos y las características de ocupación de la cavidad y aprovechamiento del entorno durante el final del VI milenio y los inicios del V milenio cal. BC.

Los resultados han mostrado el desarrollo de comunidades con una estructuración compleja y una gran adaptación a su entorno. La cavidad fue empleada por un grupo de agricultores y ganaderos, tanto como redil para el ganado como espacio doméstico y durante la práctica totalidad del año. La economía ganadera se basaría en la cría de ganado ovicaprino, explotado tanto para la obtención de carne como de leche. Esta práctica económica estaría complementada por la cría de ganado bovino y las prácticas cinegéticas.

\footnotetext{
ABSTRACT

The archaeozoological and taphonomical analyses of the faunal remains from levels 19 and 20 in the Mirador cave (Sierra of Atapuerca, Burgos) are presented. The main aim of this work is threefold: to study how faunal resources were managed, to characterize the occupation of the cave and to understand how the environmental re-

(*) IPHES. Institut Català de Paleoecologia Humana i Evolució Social. Àrea de Prehistòria. Universitat Rovira i Virgili. Pza. Imperial Tarraco 1. 43005 (Tarragona). Correo electrónico: patricia.martin@prehistoria.urv.cat

Recibido: 6-IV-2009; aceptado: 13-VII-2009.
}

sources were exploited at the end of the sixth millennium and the beginning of the fifth millennium cal. $B C$.

Results show the development of human communities with a complex organization and a great environmental adaptation. Shepherds used the cavity as a sheepfold and as a domestic space during almost all the year. Sheep and goat husbandry comprised the economic basis; these taxa were exploited mainly for their meat and milk. Breeding of cattle and hunting would have been complementary activities.

Palabras clave: Zooarqueología; Tafonomía; Neolítico Interior; Sierra de Atapuerca; Pastoreo.

Key words: Archaeozoology; Taphonomy; Inland Neolithic; Sierra de Atapuerca; Husbandry.

\section{INTRODUCCIÓN}

La Cueva del Mirador forma parte del conjunto de yacimientos, situados en el interior peninsular, que en las últimas décadas ha ayudado a mejorar el conocimiento del proceso de Neolitización en esta área. Quedan atrás los conceptos de retraso cronológico para definir este proceso o de desierto poblacional para describir el área meseteña en los inicios del Holoceno.

Las dataciones de algunos de los yacimientos más antiguos situados en esta área son equiparables a las de los yacimientos levantinos y andaluces. Las dataciones más antiguas de El Pontet, Forcas II, Chaves IB y los niveles 22 y 23 de la Cueva del Mirador sitúan las primeras ocupaciones de los grupos neolíticos en esta área en torno 
al final del VII milenio y los inicios del VI (Baldellou y Utrilla 1985; Mazo y Montes 1992; Rojo et al. 2006; Vergès et al. 2008).

Los proyectos de prospección y excavación han permitido elaborar un complejo mapa de dispersión de yacimientos al aire libre, en cueva, estaciones con arte rupestre y monumentos megalíticos, que reflejan la complejidad de la ocupación en el área meseteña desde los inicios del Holoceno (Rodanés y Ramón 1995; Rojo y Kunst 1996; Utrilla, 1996; Kunst y Rojo 1999; Muñoz 2001; Cerrillo 2005; Rojo et al. 2006).

Sin embargo, pese a estos avances en la investigación, los estudios en disciplinas como la Zooarqueología son todavía escasos. El grueso de los trabajos faunísticos de cronología neolítica se centra en los conjuntos de los yacimientos de la cuenca mediterránea y el área andaluza (Pérez Ripoll 1980; Morales y Martín 1995; Saña 1998; Bosch et al. 2000; Molist 2005; Pérez Ripoll 2006; Rojo et al. 2006).

En el Neolítico Interior destacan los estudios sistemáticos de la fauna de la Cueva de La Vaquera (Segovia) (Estremera 2003) y la Cueva de Chaves (Huesca) (Castaños 2004), así como los trabajos sobre la fauna de la Cueva del Moro de Olvena (Castaños 1991) y el valle de Ambrona (Liesau y Montero 1999).

El estudio zooarqueológico y tafonómico de los restos de macrofauna recuperados en los niveles 19 y 20 de la Cueva del Mirador tiene como principal objetivo contribuir al conocimiento sobre el Neolítico durante el final del VI milenio y los inicios el V milenio cal. BC en el interior de la Península Ibérica a partir del estudio de la organización económica del grupo y de las características de ocupación de la cavidad.

Más allá de resultados meramente económicos, los restos faunísticos pueden ofrecer también información sobre la funcionalidad y la temporalidad de la ocupación de la cavidad. Algunos autores han observado una dualidad y complementariedad en la ocupación de asentamientos, al aire libre y en cueva, en el interior peninsular. Este modelo ocupacional ha sido interpretado por algunos autores (Antona del Val 1986, 1987; Jiménez 1998) como una evidencia de la adopción de patrones de ocupación de carácter estacional, en un intento de maximización de la explotación de los recursos faunísticos mediante un pastoreo itinerante complementado por las prácticas agrícolas, cinegéticas y recolectoras. El segundo objetivo de este estudio es ofrecer información sobre esta cuestión a partir de los datos obtenidos.

\section{LA CUEVA DEL MIRADOR}

La Cueva del Mirador se encuentra en el término municipal de Ibeas de Juarros, dentro del sistema kárstico de la Sierra de Atapuerca (Burgos). Se eleva a $1.033 \mathrm{~m}$ sobre el nivel del mar y sus coordenadas geográficas son $42^{\circ} 20^{\prime} 58^{\prime \prime} \mathrm{N}$ y $03^{\circ} 30^{\prime} 33^{\prime \prime} \mathrm{O}$ (Fig. 1).

Las excavaciones sistemáticas de la cavidad se iniciaron en 1999 dentro del proyecto de «Autoecología Humana y Tecnología de los Pobladores Prehistóricos de la Sierra de Atapuerca» y continúan en la actualidad. Estos trabajos se han centrado en un sondeo de $6 \mathrm{~m}^{2}$ situado en la zona central de la mitad oeste de la superficie de la cueva que aún conserva la bóveda.

La Cueva del Mirador posee una potente sucesión holocena, compuesta por 24 niveles arqueológicos. Los niveles MIR 3 y MIR 4 fueron originados durante las ocupaciones humanas en la Edad del Bronce y los restantes (MIR6-MIR24) durante el Neolítico, a excepción de MIR5 que constituye un momento de desocupación de la cavidad. Tanto las dataciones obtenidas como el material arqueológico recuperado son coherentes con esta adscripción cultural.

Han sido realizadas un total de 17 dataciones sobre ${ }^{14} \mathrm{C}$ AMS a partir de muestras de materiales vegetales carbonizados que han situado la ocupación neolítica de la cavidad entre el 3650-3510 cal BC del nivel MIR6, y el 5210-5170 cal BC del nivel MIR24 (Vergès et al. 2008). Para la datación de los niveles estudiados en este trabajo, MIR19 y MIR20, se han empleado un fragmento de carbón de Quercus sp. (MIR19) y una semilla carbonizada de Triticum dicoccum (MIR20), que han ofrecido unas cronologías de 5210-4850 cal BC y 5230-4920 cal BC, respectivamente.

Estos dos niveles presentan unas características muy similares a los del resto de la sucesión neolítica. Durante este tiempo la cavidad fue empleada como redil para el ganado, dando lugar a una característica formación sedimentológica originada por la superposición de excrementos animales y restos vegetales y su quema periódica para el saneamiento del espacio (Angelucci et al. 2009). Se trata de una formación ampliamente documentada en contexto mediterráneo en estas 

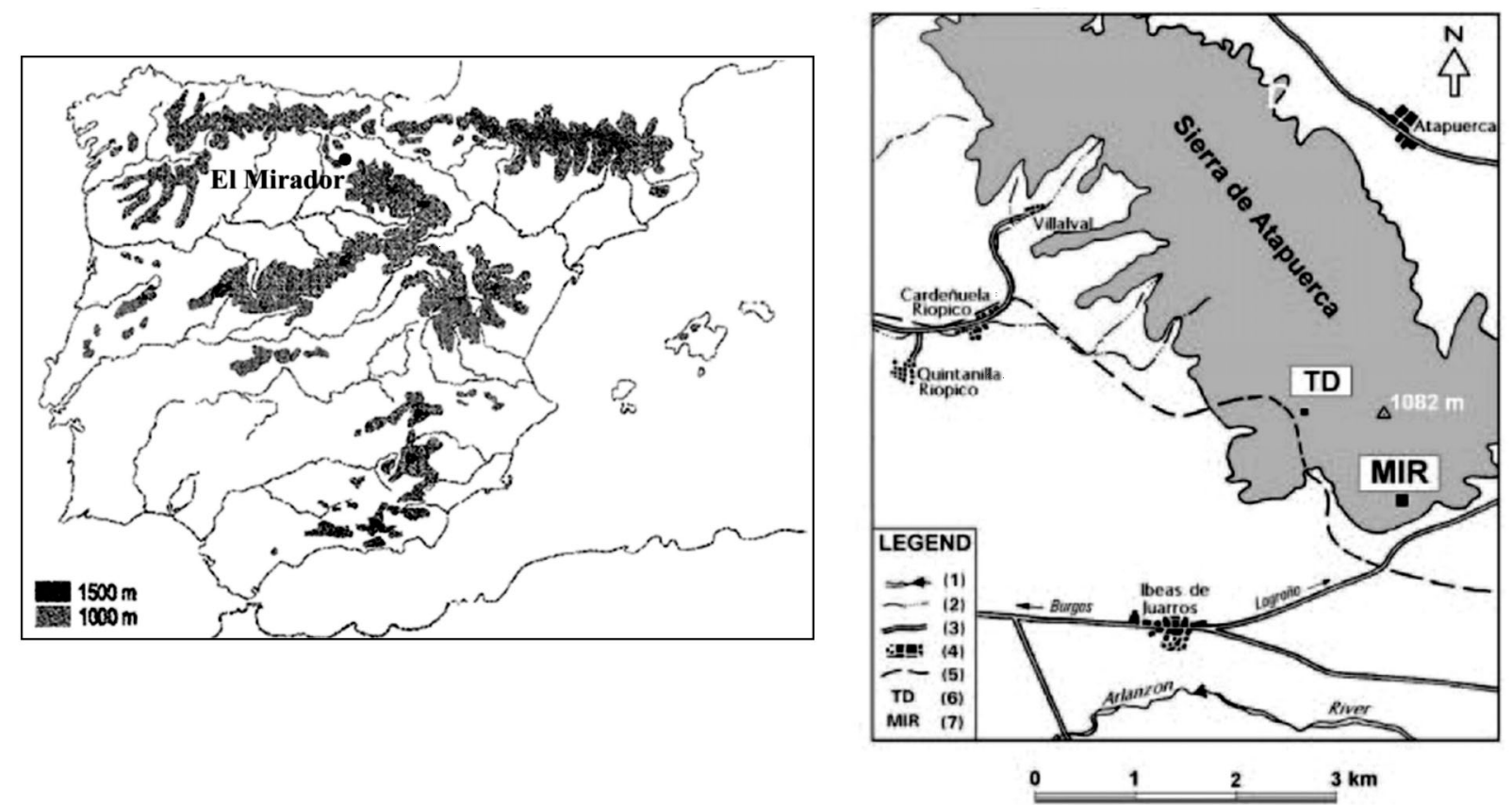

Fig. 1. Localización de la Cueva de El Mirador (modificado de Rodríguez 2004).

cronologías (Courty 1984; Badal 1999; Bergadà 1997; Bergadà et al. 2005; Karkanas 2006; Oms et al. 2008).

Los restos arqueológicos más abundantes son los paleobotánicos seguidos por los faunísticos. Los estudios de ambas disciplinas desvelan que a lo largo de toda la sucesión holocena, el grupo humano que ocupó la cavidad desarrolló una economía mixta basada en la agricultura y la ganadería.

A nivel paleoclimático, los restos paleobotánicos informan sobre la existencia de un clima templado y seco característico de estas cronologías (Allué y Euba 2008). A nivel paleoambiental, se ha documentado el desarrollo de tres biotopos en el entorno de la Cueva del Mirador. En el espacio más cercano a la cavidad, había un paisaje de bosque mixto de robles (Quercus caducifolio) y encinas (Quercus ilex-coccifera). El ambiente de ribera se encontraba en los alrededores del río Arlanzón, con taxones característicos como sauces (Salix), tilos (Tilia) y herbáceas higrófitas como las ciperáceas, anea/esparganio y la acuática Myriophyllum. Por último, la presencia entre los restos botánicos de especies cultivadas como cereales (Triticum dicoccum, Triticum aestivum/durum), leguminosas (Pisum sativum, Vicia) y otras especies sinantrópicas (Bromus sp.,
Medicago sp., Trifolium sp.) (Allué y Euba 2008; Rodríguez y Buxó 2008) indican la presencia de campos de cultivo en los alrededores de la cavidad.

Los estudios de microfauna han corroborado estos datos e informan sobre la intensidad de la ocupación antrópica con la presencia de especies antropofílicas (López-García 2008).

Los restos líticos son coherentes con su atribución cultural y con los descritos en otros yacimientos del área meseteña (Vergès et al. 2008), caracterizados por la talla laminar y la escasa transformación de los elementos. Esta misma dinámica se observa con respecto al material cerámico, entre el que se observa una predominancia de decoraciones incisas, impresiones, elementos aplicados y boquique (Vergès et al. 2008).

\section{MATERIALES Y MÉTODOS}

La identificación anatómica y taxonómica de los restos se ha realizado con la ayuda de la colección de referencia osteológica y dental del Instituto de Paleoecología Humana y Evolución Social (IPHES) y de atlas osteológicos de anatomía comparada (Barone 1969; Pales y Lambert 1970; Schmidt 1972). En el caso de aquellos ta- 
xones próximos anatómicamente como ovejas (Ovis aries) y cabras domésticas (Capra hircus) o bóvidos salvajes (Bos primigenius) y domésticos (Bos taurus) se han empleado también criterios osteométricos (Payne 1969; Driesch 1976; Jourdan 1976; Rowley-Cowny 1998; Castaños 2004).

Aquellos restos faunísticos que no presentaban los rasgos morfológicos necesarios para una identificación a nivel taxonómico y anatómico, fueron clasificados según su categoría de talla, de peso y según la categoría anatómica: huesos largos (estilopodios, basipodios, metapodios y acropodios), huesos planos (esqueleto craneal y cinturas) y huesos articulares. La clasificación según la categoría de la talla de peso de cada resto óseo se ha realizado tomando como referencia sus rasgos morfológicos (grosor del tejido cortical, tamaño global del fragmento óseo, etc.). Para este trabajo se han empleado cuatro categorías de talla de peso tomando como referencia el espectro taxonómico del conjunto y los pesos de las especies actuales correspondientes (Tab. 1).

Tras la identificación anatómica y taxonómica se ha recurrido a varios métodos de cuantificación: Número Mínimo de Individuos (NMI), Número Mínimo de Elementos (NME) y cálculo de la biomasa.

El objetivo perseguido con el cálculo del NMI y NME ha sido dar un significado a las estimaciones, medir y comprender los procesos que han sufrido los restos y reducir los efectos de la conservación diferencial. El cálculo de la biomasa o Meat Offeral Weight (MOW) tiene como objetivo valorar la importancia de los taxones identificados no por su representatividad cuantitativa sino por la cantidad de carne aportada. Este cálculo se ha realizado mediante la multiplicación de los valores de peso de masa cárnica por edad y especie, proporcionados por Vigne (1991), por el NMI de cada taxón y su correspondiente categoría de edad. En este trabajo se ha calculado la biomasa de bovinos, ovicaprinos y suidos.
Un tercer punto fundamental de este estudio zooarqueológico ha sido la determinación de la edad de muerte de los animales representados en ambos niveles, fundamentalmente la de aquellos identificados como ovicaprinos, por ser la categoría taxonómica con una muestra estadísticamente significativa para posteriores interpretaciones. Se ha empleado de forma preferente el método de determinación de edad a partir de la erupción y el desgaste dental ya que, siguiendo la tónica general de la mayoría de los yacimientos (Payne 1973; Munson 2000; Greenfield y Arnold 2008), las mandíbulas y piezas dentales mandibulares de los ovicaprinos son los elementos anatómicos mejor conservados para estos fines. Se han seguido las pautas y edades de referencia proporcionadas por Silver (1969), Payne (1973), Deniz y Payne (1982) y Grant (1982), estas últimas han sido empleadas de forma complementaria y orientativa. Los dientes que forman parte de las series dentales, tanto en mandíbulas como en maxilares, han sido analizados conjuntamente, como un solo elemento. Se han tenido en cuenta tanto dientes deciduos como definitivos siempre que presenten sus cuatro caras. El grado de desgaste dental de los dientes aislados se ha establecido a partir de la comparación con el de las series dentales completas, cuando ha sido posible.

La determinación de la edad a partir del grado de fusión ósea de los elementos del esqueleto postcraneal se ha realizado a partir de las obras Barone (1969), Silver (1969) y Noddle (1974). Los resultados, han servido en algunos casos, para matizar y completar la información aportada por la edad de erupción y desgaste dental.

La determinación del sexo no ha sido posible debido al alto índice de fragmentación del conjunto, que ha impedido la toma de medidas, y por la ausencia de elementos anatómicos distintivos como pelvis o astas y cuernos.

Además del análisis zooarqueológico propiamente dicho, también se ha llevado a cabo un

\begin{tabular}{|l|c|c|}
\hline \multicolumn{1}{|c|}{ Talla de peso } & $\begin{array}{c}\text { Rango de } \\
\text { peso }(\mathbf{k g})\end{array}$ & Especies \\
\hline Grande & $300-1500$ & Bos sp. adulto, Equus sp. adulto \\
Media & $100-300$ & Equus sp. infantil, Cervus elaphus, Bos sp. infantil \\
Pequeña & $100-15$ & Ovis aries sp., Capra hircus, Sus sp. Canis familiaris, Capreolus capreolus \\
Muy Pequeña & $<15$ & Oryctolagus cuniculus, Felis sylvestris, Vulpes vulpes \\
\hline
\end{tabular}

Tab. 1. Categoría de las tallas de peso empleadas a partir de las especies identificadas y su peso.

T. P., 66, N. ${ }^{\circ} 2$, julio-diciembre 2009, pp. 77-92, ISSN: 0082-5638

doi: $10.3989 /$ tp.2009.09024 
análisis tafonómico de los restos. Teniendo en cuenta las características del conjunto, su cronología y origen, se ha prestado una especial atención a las alteraciones de origen antrópico: marcas de corte, fracturación y alteraciones relacionadas con el tratamiento culinario de los restos (cremación y hervido).

El análisis tafonómico de los restos ha sido realizado tanto a nivel macroscópico como microscópico, con la ayuda de una lupa binocular (modelo Olimpus SZ1). Las alteraciones tafonómicas han sido identificadas, individualizadas y descritas.

Las marcas de corte han sido descritas e interpretadas según los criterios de definición, orientación y ubicación de Binford (1981) y Shipman y Rose (1983).

El análisis de la fracturación se ha realizado en todos aquellos fragmentos pertenecientes a huesos largos que superaban los $30 \mathrm{~mm}$ de longitud, a partir de las características del paño, ángulo y textura de la fractura (Morlan 1980; Villa y Mahieu 1991).

Las alteraciones tafonómicas originadas por la cremación han sido analizadas mediante los grados de coloración mientras que las alteraciones generadas por el hervido de los restos han sido estudiadas siguiendo las pautas de White (1992: 20), Botella et al. (2000) y Cáceres et al. (2007).
También se ha prestado una especial atención a las alteraciones tafonómicas originadas por la acción de los carnívoros, fundamentalmente mordeduras, atendiendo a la abundancia de éstas en el conjunto (Binford 1981; Blumenschine 1988; Andrews y Fernández Jalvo 1997; Capaldo 1998).

\section{RESULTADOS E INTERPRETACIÓN}

\section{Representación taxonómica y anatómica}

Se han estudiado un total de 1.150 restos faunísticos, 728 recuperados en MIR19 y 422 en MIR20. Se trata mayoritariamente de restos óseos (96\% del total de NR en ambos niveles), mientras que el número de restos dentales se reduce al $4 \%$ del total.

A nivel específico, han sido identificados un total de 327 restos, 202 en MIR19 y 125 en MIR20, lo que equivale al $27 \%$ y $30 \%$ del total de los restos respectivamente (Tab. 2).

La identificación taxonómica de algunos restos ha sido compleja debido a la similitud anatómica de algunas especies. El caso más significativo es el de las ovejas (Ovis aries) y las cabras domésticas (Capra hircus). Las dife-

\begin{tabular}{|l|c|c|r|r|r|r|r|r|}
\hline \multirow{2}{*}{ Taxón } & \multicolumn{2}{|c|}{ NR } & \multicolumn{2}{c|}{ NME } & \multicolumn{2}{c|}{ NMI } & \multicolumn{2}{c|}{ BIOMASA (kg) } \\
\cline { 2 - 9 } & MIR19 & MIR20 & MIR19 & MIR20 & MIR19 & MIR20 & MIR19 & MIR20 \\
\hline Bos sp. & $3(0,4)$ & $9(2,1)$ & 3 & 7 & 1 & 2 & 200 & 450 \\
Ovicaprini & $148(20,3)$ & $95(22,5)$ & 109 & 62 & 13 & 12 & 205 & 215 \\
Sus sp. & $20(2,7)$ & $10(2,3)$ & 14 & 8 & 2 & 1 & 140 & 50 \\
Equus sp. & $5(0,7)$ & $3(0,7)$ & 5 & 3 & 2 & 2 & - & - \\
Cervus elaphus & $11(1,5)$ & $3(0,7)$ & 11 & 2 & 2 & 2 & - & - \\
Capreolus capreolus & $2(0,3)$ & $0(0)$ & 2 & 0 & 2 & 0 & - & - \\
Canis familiaris & $3(0,4)$ & $0(0)$ & 3 & 0 & 1 & 0 & - & - \\
Vulpes vulpes & $1(0,1)$ & $0(0)$ & 1 & 0 & 1 & 0 & - & - \\
Felis sylvestris & $2(0,2)$ & $1(0,2)$ & 2 & 1 & 2 & 1 & - & - \\
Oryctolagus cuniculus & $7(1)$ & $3(0,7)$ & 6 & 2 & 1 & 1 & - & - \\
Aves & $0(0)$ & $1(0,2)$ & 0 & 1 & 0 & 1 & - & - \\
Talla grande & $19(2,6)$ & $8(1,8)$ & 5 & 5 & - & - & - & - \\
Talla media & $52(7,1)$ & $40(9,4)$ & 11 & 15 & - & - & - & - \\
Talla pequeña & $313(43)$ & $205(48,5)$ & 50 & 36 & - & - & - & - \\
Talla muy pequeña & $17(2,3)$ & $8(1,8)$ & 6 & 3 & - & - & - & - \\
Indeterminado & $125(17,1)$ & $36(8,5)$ & - & - & - & - & - & - \\
\hline Total & $728(100)$ & $422(100)$ & 228 & 145 & 27 & 22 & - & - \\
\hline
\end{tabular}

Tab. 2. Presentación de datos, NR (Número de Restos), NMI (Número Mínimo de Individuos), NME (Número Mínimo de Elementos) y Biomasa. Entre paréntesis, porcentajes de representación. 
rencias anatómicas en algunas mandíbulas y elementos del esqueleto postcraneal, como el calcáneo, evidencian la presencia de ambas especies en el conjunto, pero la muestra no se considera lo suficientemente amplia como para ofrecer datos cuantitativos precisos, por lo que ovejas y cabras han sido agrupadas en la categoría taxonómica de los ovicaprinos. Algo similar ocurre con los suidos y bovinos, la distinción entre las especies salvajes y domésticas es compleja por lo que han sido agrupados en las categorías Sus sp. y Bos sp., respectivamente. En cualquier caso, el único resto mesurable de bovino sugiere la existencia de un ejemplar de bovino doméstico de pequeñas dimensiones, dato compatible con los registrados en otros yacimientos contemporáneos (Tab. 4).

La categoría taxonómica más importante a nivel cuantitativo (NR, NMI y NME) es la de los ovicaprinos, seguidos por suidos, bovinos y lepóridos con valores mucho más bajos.

La categoría de talla de peso que cuenta con un mayor número de restos, en ambos niveles es la pequeña. Atendiendo a la representación específica, muy probablemente se trate de restos de ovicaprinos que debido a la fragmentación no han conservado los rasgos anatómicos necesarios para una identificación a nivel taxonómico.

La importancia representativa de cada taxón varía si se observan los resultados obtenidos tras el cálculo de la biomasa. En MIR19, la cantidad de carne proporcionada por ovicaprinos y bovinos es muy similar, sin embargo, en MIR20, la cantidad de carne de origen bovino supera ampliamente a la proporcionada por los ovicaprinos, pese a que su número de restos sea muy inferior (Tab. 2).

En lo que a la representación anatómica se refiere, los ovicaprinos aparecen representados por la práctica totalidad de los elementos anatómicos siendo las mandíbulas el elemento anatómico más abundante y el esqueleto apendicular el segmento más representado (Tab. 3). Esta dinámica es común en líneas generales, al resto de taxones.

\section{Determinación de la edad de muerte}

En MIR19 se ha podido determinar de forma precisa la edad de muerte de 214 restos $(29 \%$ del total del NR), mientras que en MIR20 esta cifra asciende a 129 restos $(30 \%)$.

\begin{tabular}{|c|c|c|c|c|c|c|c|c|c|c|c|c|c|c|c|c|c|}
\hline \multirow{2}{*}{$\begin{array}{c}\text { Categoría } \\
\text { Niv. }\end{array}$} & \multicolumn{2}{|c|}{ Bos sp. } & \multicolumn{2}{|c|}{$\begin{array}{c}\text { Ovica- } \\
\text { prini }\end{array}$} & \multicolumn{2}{|c|}{ Sus sp. } & \multicolumn{2}{|c|}{$\begin{array}{l}\text { Equus } \\
\text { sp. }\end{array}$} & \multicolumn{2}{|c|}{$\begin{array}{c}\text { Cervus } \\
\text { elaphus }\end{array}$} & \multirow{2}{*}{$\begin{array}{c}\begin{array}{c}\text { Ca- } \\
\text { preolus } \\
\text { ca- } \\
\text { preolus }\end{array} \\
19\end{array}$} & \multirow{2}{*}{$\begin{array}{c}\begin{array}{c}\text { Vulpes } \\
\text { vulpes }\end{array} \\
19\end{array}$} & \multirow{2}{*}{$\begin{array}{c}\begin{array}{c}\text { Canis } \\
\text { fami- } \\
\text { liaris }\end{array} \\
19\end{array}$} & \multicolumn{2}{|c|}{$\begin{array}{c}\text { Felis } \\
\text { sylvestris }\end{array}$} & \multicolumn{2}{|c|}{$\begin{array}{c}\text { Orycto- } \\
\text { lagus } \\
\text { cuniculus }\end{array}$} \\
\hline & 19 & 20 & 19 & 20 & 19 & 20 & 19 & 20 & 19 & 20 & & & & 19 & 20 & 19 & 20 \\
\hline Cráneo & - & - & 2 & 3 & 5 & 2 & - & - & - & - & - & - & - & - & - & 1 & - \\
\hline Maxilar & - & - & 10 & 4 & - & 3 & - & - & 1 & - & - & - & 1 & 1 & - & - & - \\
\hline Mandíbula & 1 & - & 25 & 18 & 4 & 1 & 2 & - & 1 & 2 & 1 & - & - & - & 1 & - & - \\
\hline Diente & - & - & 1 & - & 1 & - & 1 & 1 & 1 & - & - & - & - & - & - & - & - \\
\hline Hioides & - & - & 3 & 1 & - & - & - & - & - & - & - & - & - & - & - & - & - \\
\hline Vértebra & - & - & 4 & 4 & - & - & - & - & 2 & - & - & - & 1 & - & - & - & - \\
\hline Escápula & - & - & 5 & 3 & - & - & - & - & - & - & - & - & - & - & - & - & - \\
\hline Coxal & - & - & 2 & - & - & 1 & - & - & - & - & - & - & - & - & - & 1 & 2 \\
\hline Húmero & - & - & 8 & 8 & - & - & - & - & 2 & - & - & - & - & - & - & - & - \\
\hline Radio & - & - & 4 & 8 & 1 & - & - & 1 & - & - & - & - & - & - & - & 1 & 1 \\
\hline Ulna & - & 1 & 2 & 3 & - & - & - & - & - & - & - & - & - & - & - & 1 & - \\
\hline Fémur & - & - & 10 & 8 & 1 & - & - & - & - & - & - & - & - & - & - & - & - \\
\hline Tibia & - & 2 & 11 & 8 & 1 & - & - & - & - & - & - & - & - & - & - & 2 & - \\
\hline Fíbula & - & - & 2 & 1 & 1 & 1 & - & - & - & - & - & - & - & - & - & - & - \\
\hline Carpal/Tarsal & 1 & 2 & 22 & 8 & 1 & - & - & 1 & 2 & 1 & - & - & - & - & - & - & - \\
\hline Metápodo & 1 & 1 & 21 & 13 & 4 & 2 & 1 & - & - & - & 1 & - & 1 & 1 & - & 1 & - \\
\hline Falange & - & 1 & 16 & 3 & 1 & - & 1 & - & 2 & - & - & 1 & - & - & - & - & - \\
\hline Total & 3 & 7 & 148 & 95 & 20 & 10 & 5 & 3 & 11 & 3 & 2 & 1 & 3 & 2 & 1 & 7 & 3 \\
\hline
\end{tabular}

Tab. 3. Representación del NR identificado en MIR19 y MIR20 según la categoría anatómica y taxonómica. 


\begin{tabular}{|c|c|c|c|c|c|}
\hline MIR20 & & & & & \\
\hline Astrágal & & & & & \\
\hline $\begin{array}{l}\text { LT } \\
\text { DTdis }\end{array}$ & $\begin{array}{l}60 \\
35.8\end{array}$ & & Bos taurus & & $\begin{array}{c}\text { Bos } \\
\text { Primigenius }\end{array}$ \\
\hline DTprox & 41,8 & & Cueva & & \\
\hline DDPm & 32 & Chaves & del Moro & (Altuna y & Chaves \\
\hline DDP1 & 31,5 & 2004) & $\begin{array}{c}\text { (Castaños } \\
\text { 1991) }\end{array}$ & $\begin{array}{c}\text { Mariezkurena } \\
\text { 2001) }\end{array}$ & 2004) \\
\hline & $\mathbf{L T}$ & $\begin{array}{c}66,5 ; \\
59,5 ; 60 ; 59,5\end{array}$ & 66,5 & 63,$5 ; 61,5 ; 61$ & 78 \\
\hline & DTdis & $40 ; 36 ; 37 ; 36$ & 43,5 & 43,5 & 52 \\
\hline & DDP1 & $40 ; 36 ; 37 ; 36$ & 40,5 & 39,$0 ; 36,5 ; 35 ; 36$ & 45 \\
\hline
\end{tabular}

Tab. 4. Comparación de los datos osteométricos (en $\mathrm{mm}$ ) obtenidos a partir de los restos óseos de bovino de la Cueva de El Mirador con los datos disponibles de otros yacimientos de cronología similar. Abreviaturas: LT (longitud total), DT (diámetro transversal), DDP (diámetro dorso-plantar), prox. (proximal), dist. (distal).

Los ovicaprinos son la categoría taxonómica que ha proporcionado una mayor información (Tab. 5). Si se observa el NMI por categoría de edad se aprecia que las dos más numerosas son las compuestas por los individuos infantiles y juveniles (Fig. 2). Concretamente, en MIR19, la cohorte de edad más numerosa es la de los individuos que se encuentran entre el primer y segundo año de vida, mientras que en MIR20, los individuos que se encuentran en su primer año de vida son los más abundantes. Destaca también la presencia de dos individuos neonatos.

\section{Análisis tafonómico}

Los resultados del análisis tafonómico son muy similares en ambos conjuntos. Predominan las alteraciones de origen antrópico, como cabía esperar atendiendo a la cronología de los conjuntos (Lám. I).

La alteración tafonómica identificada en un mayor número de restos es la fragmentación (90\% en MIR19 y $91 \%$ en MIR20). Se han analizado un total de 358 paños de fractura en MIR19 y 237 en MIR20. En ambos niveles, pre-

\begin{tabular}{|l|c|c|c|c|c|c|c|c|}
\hline \multirow{2}{*}{\multicolumn{1}{c|}{$\begin{array}{c}\text { Nivel/edad } \\
\text { Taxones }\end{array}$}} & \multicolumn{9}{c|}{ MIR19 } & \multicolumn{4}{c|}{ MIR20 } \\
\cline { 2 - 9 } & Neo. & Inf. & Juv. & Ad. & Neo. & Inf. & Juv. & Ad. \\
\hline Bos sp. $\left(^{*}\right)$ & - & - & 1 & - & - & 1 & - & 1 \\
Ovicaprini $(+)$ & 1 & 3 & 7 & 2 & 1 & 6 & 3 & 2 \\
Sus sp. $\left(^{*}\right)$ & - & 1 & - & 1 & - & - & 1 & - \\
Equus sp. $(*)$ & - & - & - & 2 & - & - & - & 2 \\
Cervus elaphus $(*)$ & - & 1 & - & 1 & - & 1 & - & 1 \\
Capreolus capreolus $(*)$ & - & 1 & - & 1 & - & - & - & - \\
Canis familiaris $(*)$ & - & - & - & 1 & - & - & - & - \\
Vulpes vulpes & - & - & - & 1 & - & - & - & - \\
Felis sylvestris $(*,+)$ & - & 1 & - & 1 & - & - & - & 1 \\
Oryctolagus cuniculus $(*)$ & - & 1 & - & - & - & 1 & - & - \\
\hline
\end{tabular}

Tab. 5. Presentación del NMI por taxón y edad. $(*)$ edad determinada a partir de los datos proporcionados por el estado de fusión ósea. $(+)$ edad determinada a partir de los datos proporcionados por el estado de erupción y desgaste dental. Abreviaturas: Neo. (neonato: 0-1 mes), Inf. (infantil: 1-6 meses), Juv. (juvenil: 6-36 meses), Ad. (adulto: 36 meses en adelante). 


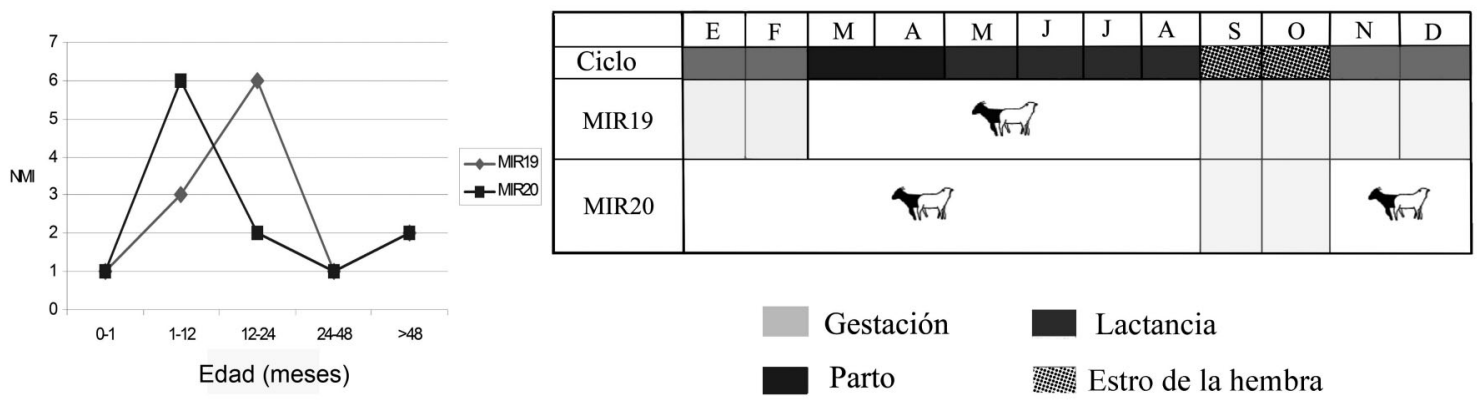

Fig. 2. A la izquierda, representación gráfica del NMI del ganado ovicaprino de los niveles 19 y 20 según intervalos de edad. A la derecha cuadro cuadro comparativo entre el ciclo vital de los ovicaprinos según Jensen (2004) y estacionalidad de la ocupación de la cavidad estimada a partir de la edad de muerte de estos animales en los niveles 19 y 20.
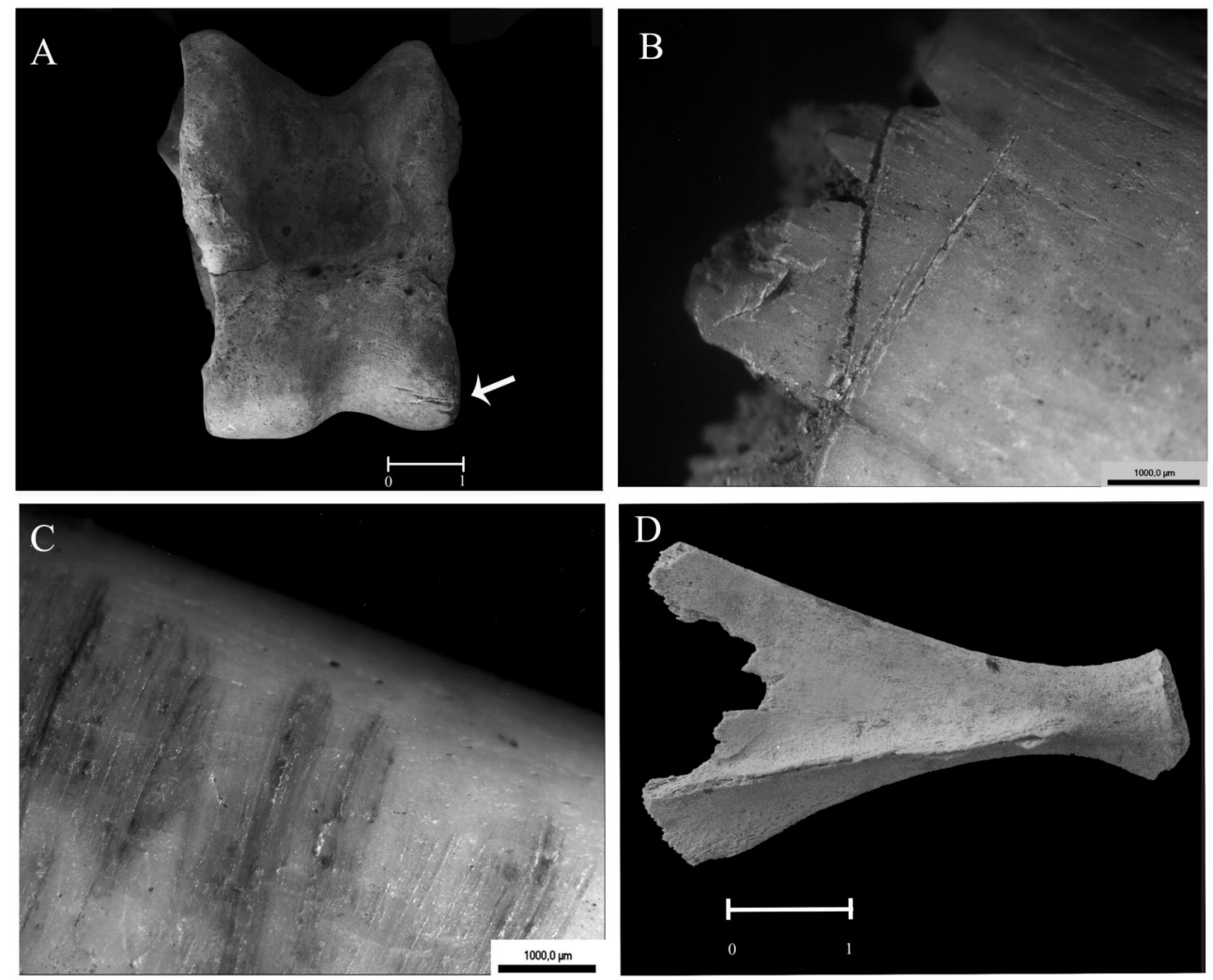

Lám. I. A. Astrágalo de bovino con incisión en la tróclea distal. B. Incisión sobre la cara externa de una costilla de talla pequeña. C. Abrasión de yunque sobre una ulna de bovino. D. Evidencia de mordedura sobre una escápula de ovicaprino. 
dominan las fracturas en fresco (delineación curvada, ángulo oblicuo y textura suave). Además, en torno al $5 \%$ del total de restos de ambos conjuntos presenta evidencias de fracturación antrópica, como estigmas de percusión o abrasiones de yunque. Todas estas características permiten plantear al hombre como principal agente fracturador del conjunto, sin descartar otros agentes, como los perros, o procesos diagenéticos, como el pisoteo del ganado.

Las alteraciones de origen térmico son las segundas en importancia cuantitativa. El $83 \%$ de estos restos presenta las características alteraciones originadas por el hervido de los huesos: el pulido o pot polish (White 1992) en los bordes de fractura, así como el aspecto translúcido del hueso (Botella et al. 2000). Destaca el hecho de que estas alteraciones estén presentes en prácticamente todos los taxones, incluyendo aquellos cuyo consumo humano es poco frecuente en esta época, como el del perro (Canis familiaris).

Los restos con evidencias de cremación representan un pequeño porcentaje en ambos conjuntos (14\% del NR de MIR19 y el $16 \%$ en MIR20). La mayoría de los restos presentan una coloración de tono marrón más o menos homogénea que se relaciona con una exposición breve a la acción del calor. En algunos casos se han identificado también dobles coloraciones en la misma superficie ósea, relacionados con el cocinado del hueso con carne.

El porcentaje de restos en los que se han identificado marcas de corte es también relativamente alto, un $7 \%$ en MIR19 y un $10 \%$ en MIR20, concentrándose en el esqueleto apendicular y axial. Se han identificado marcas de corte en restos de bovino, suidos, équidos y ovicaprinos. En el caso de estos últimos, debido a su abundancia y según su tipología, orientación y distribución de las marcas de corte, se ha podido documentar la cadena operativa de procesamiento faunístico al completo (despellejamiento, evisceración, descuartizamiento, desarticulación, descarnación).

Las mordeduras son numerosas en ambos niveles $(21 \%$ de NR en ambos conjuntos) especialmente, los surcos y depresiones en diáfisis situadas preferentemente, en los elementos del esqueleto axial y apendicular (Lám. I). Teniendo en cuenta la presencia de perros acompañando al grupo humano, se considera que estos son el principal agente responsable de estas alteraciones, si bien en algunos casos, no se descartan posibles mordeduras como la acción de otros animales o incluso, del hombre.

\section{DISCUSIÓN}

\section{La estructuración económica del grupo}

La representación taxonómica obtenida a partir del análisis faunístico de los restos de los niveles 19 y 20 de la Cueva del Mirador se caracteriza por la presencia de especies salvajes y domésticas y por la predominancia clara de los restos de ovicaprinos en ambos conjuntos. El resto de taxones aparece representado de forma residual. Entre ellos se encuentran restos cuya adscripción a un origen salvaje o doméstico es, a priori dudosa, como équidos, bovinos y suidos, así como de taxones de claro origen doméstico, como el perro, y salvaje, como corzos, ciervos o conejos.

Este espectro faunístico es muy similar al identificado en otros yacimientos peninsulares con una cronología similar, ubicados tanto en el área interior (Estremera 2003; Castaños 2004; Cerrillo 2005), como en la cuenca mediterránea y el área andaluza (López y Molero; 1984, Morales y Martín 1995; Pérez Ripoll 1980; Bosch et al. 2000)

Los restos de ganado ovicaprino dominan gran parte de los conjuntos faunísticos del Neolítico peninsular. Desde un punto de vista económico, la cría conjunta de cabras y ovejas es complementaria y altamente productiva, convirtiéndose, a lo largo de la historia, en la base del pastoreo mediterráneo (Montoya 1983). Estas dos especies presentan una gran capacidad de adaptación a los pastos mediterráneos y una gran capacidad reproductiva, siendo su cría económica incluso en momentos de escasez (Montoya 1983; Jensen 2004).

La abundancia de restos de ovicaprinos, en ambos conjuntos de la Cueva del Mirador, ha permitido profundizar en las características de la explotación económica de esta categoría taxonómica. Según los estudios de determinación de edad de muerte, el $75 \%$ de los individuos fue sacrificado en sus dos primeros años de vida. Este patrón se relaciona con la explotación primaria de estos animales ya que es en este momento cuando se optimiza la cantidad de carne obtenida respecto al esfuerzo invertido (Uerpmann 1973; Davis 1989; Molist 2005). Se trata del patrón observado también en gran parte de los yacimientos penin- 
sulares contemporáneos (Castaños 1991; Morales y Martín 2003; Castaños 2004; Molist 2005).

La presencia de individuos infantiles (1-6 meses) en ambos niveles, se relaciona también con la explotación láctea de estos animales. El período de lactancia de los ovicaprinos, salvajes y domésticos se prolonga entre los 4 y 8 primeros meses de vida (Montoya, 1983; Jensen, 2004), por lo que el sacrificio de animales con esta edad permitiría el aprovechamiento humano de la leche. Por lo tanto, se puede afirmar que la cría de ovicaprinos de los niveles 19 y 20 de la Cueva del Mirador tendría un carácter mixto.

En líneas generales, la cría de ganado bovino, desempeña un papel secundario en la mayoría de los yacimientos peninsulares (Pellicer y Morales 1995; Morales y Martín 2003; Castaños 2004; Pérez Ripoll 2006). Desde un punto de vista económico, la cría de ganado bovino es menos rentable que la del ovicaprino, sin embargo, es más sencilla en lo que a la inversión de mano de obra se refiere (Montoya 1983), fundamentalmente porque los rebaños están compuestos por un número menor de cabezas de ganado. Se considera que los restos de bóvido recuperados en ambos niveles del Mirador, corresponden a la especie doméstica (Bos taurus). Si bien el número de restos es escaso, los datos osteométricos son muy significativos, y el tamaño de los bovinos es muy similar al de los bovinos domésticos determinados en otros yacimientos alejándose bastante de las dimensiones de los bóvidos salvajes (Bos primigenius) (Tab. 4).

Los datos proporcionados por los cálculos de biomasa, los arqueobotánicos y las características de la cueva serían coherentes con este planteamiento. Los bovinos aportarían la misma cantidad de carne que los ovicaprinos en MIR19 y la superarían en MIR20, por lo tanto, la cría de unas cuantas cabezas de ganado bovino sería tan rentable como la del rebaño de ovicaprinos, más numeroso. El entorno de la cueva cumpliría con las condiciones necesarias para la cría de este taxón. El ganado bovino podría alimentarse en la zona de ribera del río Arlanzón, situado a pocos kilómetros de la cueva, biotopo llano, con agua y pastoreo herbáceo. También se han identificado especies vegetales cultivadas exclusivamente para la alimentación del ganado, como el bromo (Bromus sp.), la cizaña (Lolium sp.) o el trébol (Trifolium sp.) y no se descarta la posibilidad de que el ganado bovino se alimentara también de los campos de cultivo, cumpliendo con la doble función de abonado y oxigenado de las tierras (Halstead 1981).

La distinción entre la especie doméstica y el agriotipo en los suidos y équidos del Mirador no ha sido posible. Los restos son escasos y los datos osteométricos no han sido concluyentes. Se trata de una problemática común a muchos de los yacimientos peninsulares contemporáneos, especialmente en el caso del caballo aunque teniendo en cuenta la cronología, muy probablemente los restos de équidos recuperados en MIR19 y MIR20 corresponderían al agriotipo salvaje (Liesau 2005).

La fauna salvaje está representada por especies de mamíferos de bosque y serranía, procedentes muy probablemente del entorno de la cavidad, como ciervos, corzos y conejos. Teniendo en cuenta el número de restos por el que aparecen representadas estas especies, la caza debió desempeñar un papel secundario dentro de las actividades económicas del grupo de pastores y agricultores. No obstante no se ha de desdeñar la importancia de estos taxones como complemento en la dieta y la economía de estos grupos.

\section{El procesamiento de las carcasas y la ocupación de la cavidad}

El análisis anatómico y tafonómico de los restos de ovicaprino recuperados en los niveles neolíticos 19 y 20 ha proporcionado los datos necesarios para afirmar el empleo de la cavidad como espacio para el desarrollo de actividades domésticas relacionadas con el procesamiento de ovejas y cabras. Esta hipótesis ya había sido planteada para los niveles de la Edad del Bronce (Vergès et al. 2002).

El estudio de las marcas de corte, fracturación y de la representación anatómica de los restos de ovicaprino ha permitido documentar al completo la cadena operativa del procesamiento de estos animales.

A través de la distribución, orientación y disposición de las marcas de corte se han documentado todas las actividades relacionadas con la preparación y posterior procesamiento de las carcasas de los ovicaprinos para la extracción de los recursos externos: despellejamiento, descuartizamiento, evisceración, descuartizamiento y descarnación (Tab. 6). La descarnación ha sido el proceso documentado en un mayor número de restos, mediante incisiones y aserrados, localizados en 


\begin{tabular}{|c|c|c|c|c|c|c|c|c|c|c|c|c|c|c|}
\hline & \multicolumn{2}{|c|}{ Bos sp. } & \multicolumn{2}{|c|}{ Ovicaprini } & \multirow{2}{*}{$\begin{array}{c}\begin{array}{c}\text { Sus } \\
\text { sp. }\end{array} \\
19\end{array}$} & \multicolumn{2}{|c|}{ Equus sp. } & \multirow{2}{*}{$\begin{array}{r}\text { T.g. } \\
19\end{array}$} & \multicolumn{2}{|c|}{ Talla media } & \multicolumn{2}{|c|}{ Talla pequeña } & \multicolumn{2}{|c|}{ Indet. } \\
\hline & 19 & 20 & 19 & 20 & & 19 & 20 & & 19 & 20 & 19 & 20 & 19 & 20 \\
\hline Cráneo & - & - & - & - & - & - & - & - & - & $1(3 i)$ & - & $2(2 \mathrm{i})$ & - & - \\
\hline Mandíbula & - & - & $3(4 \mathrm{i})$ & - & $2(2 i)$ & - & - & - & - & - & - & - & - & - \\
\hline Vértebra & - & - & - & - & - & - & - & 1(1i) & - & - & $2(9 \mathrm{i})$ & $1(4 i)$ & - & - \\
\hline Costilla & - & - & $2(2 \mathrm{i})$ & - & - & - & - & $1(1 \mathrm{i})$ & $2(1 \mathrm{r})$ & $1(2 \mathrm{i})$ & $\begin{array}{c}14 \\
(29 i \cdot 5 t \cdot 5 a)\end{array}$ & $\begin{array}{c}13 \\
(24 \mathrm{i} \cdot 1 \mathrm{t})\end{array}$ & - & - \\
\hline Escápula & - & - & $1(3 i)$ & - & - & - & - & - & _- & - & - & - & - & - \\
\hline Húmero & - & - & $2(8 i ; 1 a)$ & $2(6 i)$ & - & - & - & - & - & $1(7 \mathrm{i})$ & - & - & - & - \\
\hline Radio & - & - & - & $\begin{array}{c}1 \\
(1 \mathrm{t} ; 2 \mathrm{i})\end{array}$ & - & - & 1(1i) & - & - & $1(5 i)$ & - & - & - & - \\
\hline Ulna & - & $1(3 i)$ & - & - & - & - & - & - & - & - & - & - & - & - \\
\hline Coxal & - & - & $2(2 \mathrm{i})$ & & - & - & - & - & - & - & - & - & - & - \\
\hline Fémur & - & - & $2(1 \mathrm{a}$ y $4 \mathrm{i})$ & $2(2 a)$ & - & - & - & - & - & - & - & - & - & - \\
\hline Tibia & - & - & - & - & $1(2 \mathrm{i})$ & - & - & $1(2 \mathrm{i} ; 1 \mathrm{a})$ & - & - & - & - & - & - \\
\hline Metápodo & $1(2 \mathrm{i})$ & 1(1i) & $4(7 \mathrm{i})$ & $3(11 i)$ & - & $1(8 \mathrm{i})$ & - & - & - & - & - & - & - & - \\
\hline Carpal/Tarsal & - & $1(2 \mathrm{i})$ & $1(5 \mathrm{i})$ & - & - & - & - & - & - & - & - & - & - & - \\
\hline H. largo & - & - & - & - & - & - & - & - & $2(4 \mathrm{i} ; 1 \mathrm{a})$ & $2(5 \mathrm{i})$ & $5(8 i)$ & $5(9 \mathrm{i})$ & - & - \\
\hline H. plano & - & - & - & - & - & _- & _ & - & - & - & 1(1i) & - & - & - \\
\hline Indet. & - & - & - & - & - & - & - & - & - & - & - & - & $2(2 \mathrm{i})$ & $2(3 i)$ \\
\hline
\end{tabular}

Tab. 6. Presentación del NR por especies, elemento anatómico y nivel en los que se han identificado marcas de corte. Entre paréntesis, número y tipo de marca identificada en estos restos. Abreviaturas: i (incisión), a (aserrado), r (raspado), t (tajo); T.g. (Talla grande); H. (Hueso); Indet. (Indeterminado).

estilopodios y zigopodios y en la cara externa de las costillas.

En lo que respecta a la representación anatómica, los elementos del esqueleto apendicular, ricos en contenido cárnico, son los más abundantes. Sin embargo, hay que destacar también la importancia de la presencia de elementos anatómicos pobres en nutrientes como las mandíbulas, los hioides o los acropodios y basipodios de individuos neonatos. Esta representación anatómica confirma la ausencia del schleep effect o transporte diferencial (Perkins y Daly 1968; Gifford et al. 1980) en ambos conjuntos. Asimismo, las etapas de procesamiento primario, como el despellejamiento o el descuartizamiento no suelen documentarse en aquellos conjuntos que son fruto del transporte diferencial de las carcasas.

La intensa fracturación que presentan ambos conjuntos faunísticos así como las evidencias de fracturación antrópica, son indicios del procesamiento de los recursos faunísticos en el interior de la cavidad con el fin de obtener recursos internos (grasa, médula) y en algunos casos, como parte de la cadena operativa de producción para obtener útiles de hueso, a tenor de los fragmentos óseos con pulimento antrópico recuperados.

El procesamiento culinario de los recursos faunísticos en el interior de la cavidad culminaría con el hervido de los huesos, en la mayor parte de los casos. Las alteraciones tafonómicas asociadas al hervido están presentes en una gran cantidad de restos y en todos los taxones y categorías de talla de peso. Se descarta así la posibilidad de que la presencia de algunos taxones salvajes en el conjunto se deba a causas naturales.

Destaca también el hecho de que los restos de perro (Canis familiaris) recuperados presentan evidencias de haber sido hervidos. El escaso número de restos por los que suele aparecer representado este taxón en los yacimientos neolíticos es atribuido a que este animal acompañaba al grupo humano pero no formaba parte de su dieta (Munsil 1984; Molist 2005). Esta relación de simbiosis, perro-hombre, queda constatada en la Cueva del Mirador a través de los huesos de este taxón recuperados y del alto número de restos que presentan mordeduras de cánidos. Sin embargo, parece que en el nivel 19 se produjo un consumo puntual de este animal, hecho documentado en algunos otros yacimientos holocenos (Harcourt y Kent 1974; Clutton-Brock y Hammond 1994; García-Moncó 2008).

\section{Estacionalidad}

Se ha realizado un estudio de la temporalidad de la ocupación de la cavidad a partir de los pa- 
trones de edad de muerte de los ovicaprinos y los datos que se disponen sobre el ciclo vital de estos animales en la actualidad (Jensen 2004). Manteniendo la misma línea que se ha ido planteando en este trabajo, el estudio se ha centrado en los restos de ovicaprinos por ser la especie que aporta un mayor número de restos. En cualquier caso, es necesario precisar que se trata de una primera aproximación a la espera del análisis completo de la sucesión neolítica de la cavidad, que proporcione un mayor volumen de restos para realizar este estudio tanto a partir de la información proporcionada por este y otros taxones, domésticos o salvajes.

Los patrones de edad de los ovicaprinos, obtenidos a partir del análisis zooarqueológico de los niveles 19 y 20 de la Cueva del Mirador, ofrecen dos patrones de ocupación diferentes.

Actualmente, los partos de cabras y ovejas tienen lugar en los meses de primavera, fundamentalmente durante marzo y abril (Jensen 2004) (Fig. 2). Teniendo en cuenta este dato y las edades de muerte de los ovicaprinos identificados en MIR19, la ocupación de la Cueva del Mirador, en este momento, se iniciaría en primavera y continuaría en los meses de verano. Sin embargo, los datos obtenidos en MIR20 informan sobre una ocupación prolongada durante la práctica totalidad del año (Fig. 2).

La ocupación de las tierras altas durante el verano por parte de los pastores y el ganado es una práctica ampliamente documentada, histórica y etnográficamente, en la Península Ibérica. Este patrón podría explicar el tipo de ocupación observado en MIR19 y por lo tanto, que el entorno de la Cueva del Mirador fuera empleado como pastos de altura por pastores procedentes de áreas con menos altitud, como las cuencas del Duero y del Ebro. Una segunda explicación a este patrón, y teniendo en cuenta la proximidad de sistemas montañosos más altos, como la Sierra de la Demanda (2000 m sobre el nivel del mar, aproximadamente), es que el entorno de la Cueva del Mirador fuera empleado por grupos de la misma zona que se desplazaran a la misma altura durante todo el año, buscando los mejores pastos.

El patrón observado en MIR20 parece indicar la presencia humana en la cavidad durante la práctica totalidad del año.

Según los resultados obtenidos a través del estudio zooarqueológico ambos patrones de ocupación son compatibles. Sin embargo, las caracte- rísticas ecológicas del entorno y las condiciones económicas del grupo inducen a considerar más probable el patrón observado en MIR20, es decir, una ocupación estable durante la práctica totalidad del año.

El sistema económico mixto agroganadero, desarrollado por el grupo humano que ocupó la cavidad, exigiría una permanencia estable en la misma y sus alrededores a lo largo de todo el año. Los restos carpológicos no han ofrecido datos concluyentes sobre la temporalidad de la ocupación pero según las especies cultivadas sí que se constata la necesidad de ocupación de la cavidad en los meses de otoño para la cosecha.

Por otra parte, taxones domésticos, como los bovinos, poco andariegos y altamente adaptados a los pastos altos y densos de llanuras y vaguadas (Montoya 1983; Jensen 2004), están informando también sobre la presencia continuada en la cavidad de al menos una parte del grupo, dedicada al cuidado de las tierras de cultivo y de este tipo de ganado. No obstante, no se descartan los desplazamientos puntuales con el ganado ovino y caprino dirigido por un pastor o grupos de pastores en épocas de escasez, como se ha documentado etnográficamente (Violant i Simorra 1986; Moreno 1999). Este sistema agroganadero correspondería al definido por Khazanov (1984) como "pastores semisedentarios".

El entorno vegetal de la cavidad (bosque mixto y ribera de río) proporcionaría los recursos vegetales suficientes para el mantenimiento del ganado al menos en los meses de verano. Durante los meses de invierno el ganado ovino y caprino consume más recursos leñosos y se hace más ramoneador (Montoya 1983) y podría alimentarse de los recursos leñosos de la sierra. La sucesión neolítica de la Cueva del Mirador ha proporcionado una importante cantidad de restos de roble, documentados a través del estudio antracológico. Esta abundancia ha sido relacionada con la utilización de este taxón como combustible y como alimentación para el ganado (Allué y Euba 2008). Un patrón similar ha sido identificado en varios yacimientos del área mediterránea, donde la abundancia de acebuche ha sido interpretada como el empleo de este taxón para la alimentación del ganado ovicaprino y bovino (Badal 1999).

Por otra parte, como ya ha sido planteado para el ganado bovino, los ovicaprinos habrían sido alimentados también de especies vegetales culti- 
vadas e identificadas en el registro carpológico (cizaña, bromo o trébol) de la cavidad (Rodríguez y Buxó 2008) y las propias tierras de cultivo podrían haber servido también como alimento (Halstead 1981).

La amplitud de la cavidad permitiría alojar tanto a la comunidad humana como al ganado durante todo este tiempo.

Los datos proporcionados por otros yacimientos de cronología y características similares, como la Cueva de La Vaquera (Estremera 2003) y la Cueva de El Moro de Olvena (Utrilla y Baldellou 1996), informan de un aprovechamiento mixto del territorio. Se propone una ocupación estival para estas dos cuevas, complementada por la ocupación invernal en otros yacimientos de menor altitud y relacionados con la explotación agrícola.

\section{CONCLUSIONES}

El estudio zooarqueológico y tafonómico de los niveles 19 y 20 de la Cueva del Mirador (Sierra de Atapuerca, Burgos) ha permitido profundizar en el conocimiento de la gestión de los recursos faunísticos y la complejidad de las comunidades humanas que poblaron la Meseta a finales del VI milenio y principios del $\mathrm{V}$ milenio cal. BC.

Las similitudes de ambos conjuntos indican una continuidad en la estructuración económica del grupo así como en las características temporales y funcionales de la ocupación de la cavidad durante todo este período.

El grupo humano que ocupaba la cavidad se encontraba plenamente inmerso dentro de un sistema de producción agroganadera. Según los datos faunísticos, la base del aprovechamiento faunístico la constituía la cría de ganado ovicaprino y de un pequeño grupo de cabezas de ganado bovino. La caza desempeñaría un papel secundario en la economía de estos grupos, que aprovecharían las especies cinegéticas de su entorno.

Los datos sobre la edad de sacrificio de los ovicaprinos han desvelado que estos eran explotados tanto para la obtención de carne como de leche. Según los datos de biomasa, se considera que el bovino era criado también para su aprovechamiento cárnico aunque no se descarta la obtención de otros productos secundarios (como la leche y la fuerza de trabajo) si bien, esto no ha sido documentado.
Con el objetivo de extrapolar la información estrictamente faunística a cuestiones relacionadas con la ocupación de la cavidad así como con la capacidad de adaptación del grupo humano a su entorno se han extraído varias conclusiones.

La Cueva del Mirador fue empleada no sólo como redil para el ganado, sino también como espacio doméstico por parte de la comunidad humana. Se han documentado diversas actividades relacionadas con la vida cotidiana, el procesamiento y el consumo de los animales.

A la espera de un análisis más amplio de la sucesión neolítica, se considera que el grupo de pastores que ocupó la cavidad lo hizo durante todo el año, desarrollando un sistema de pastoreo semisedentario. Las características del ganado, el entorno vegetal de la cavidad y los recursos vegetales permitirían la ocupación de la cavidad incluso en los meses de escasez hibernales. De ser así, el grupo de pastores y agricultores del Mirador habría desarrollado un sistema económico complejo en el que demostraría una buena adaptación y explotación de su entorno así como una adopción consolidada de las nuevas técnicas de producción, dentro de los momentos más antiguos de ocupación neolítica del interior peninsular.

\section{AGRADECIMIENTOS}

Agradecemos al Dr. Jordi Nadal sus correcciones y sus aportaciones a este texto.

\section{BIBLIOGRAFÍA}

Allué, E. y Euba, I. 2008: "Los datos antracológicos de la secuencia neolítica del Mirador (Atapuerca, Burgos): Un estudio sobre el medio vegetal y la explotación de las especies vegetales leñosas". Actas del IV Congreso del Neolítico Peninsular (Alicante 2007): 345-352. Alicante.

Andrews, P. y Fernández Jalvo, Y. 1997: “Surface modifications of the Sima de los Huesos fossil humans". Journal of Human Evolution 33: 191-217.

Angeluci, D. E.; Boschian, G.; Fontanals, M.; Pedrotti, A. y Vergès, J.M. 2009: "Shepherds and karst: the use of caves and rock-shelters in the Mediterranean region during the Neolithic". World Archaeology 41 (2): 191-214.

Antona del Val, V. 1986: "Aproximación a la problemática del neolítico en la Meseta: una propuesta de la secuencia cultural". Wad-Al-Hayara 13: 9-45. 
Badal, E. 1999: "El potencial pecuario de la vegetación mediterránea: las Cuevas Redil”. Saguntum Extra-2: 69-75.

Baldellou, V. y Utrilla, P. 1985: "Nuevas dataciones de radiocarbono de la Prehistoria oscense". Trabajos de Prehistoria 42: 83-95.

Barone, R. 1969: Anatomie comparée des mammifères domestiques. Osteologie. Masson. París.

Bergadà, M.M. 1997: “Actividad antrópica en el Neolítico Antiguo Catalán a través del análisis micromorfológico". Trabajos de Prehistoria 54 (2): 151-162.

Bergadà, M.M.; Cebrià, A. y Mestres, J. 2005: "Prácticas de estabulación durante el Neolítico Antiguo en Cataluña a través de la micromorfología: Cueva de la Guineu (Font-Rubí, Alt Penedès, Barcelona)". En Actas del III Congreso del Neolítico en la Península Ibérica (Santander 2003). Publicaciones de la Universidad de Cantabria: 187-196. Santander.

Binford, L.R. 1981: Bone: Ancient Men and Modern Myths. Academic Press. Orlando.

Blumenschine, R.J. 1988: “An Experimental Model of the Timing of Hominid and Carnivore Influence on Archaeological Bone Assemblages". Journal of Archaeological Science 15: 483-502.

Bosch, A.; Tarrús, J. y Chinchilla, J. (coord.) 2000: El poblat lacustre neolitic de la Draga. Excavations de 1990 a 1998. Generalitat de Catalunya. Girona.

Botella, M.C.; Alemán, I. y Jiménez, S.A. 2000: Los huesos humanos. Manipulación y alteraciones. Ediciones Bellaterra. Barcelona.

Cáceres, I.; Lozano, M. y Saladié, P. 2007: “Evidence for Bronze Age Cannibalism in El Mirador Cave (Sierra de Atapuerca, Burgos, Spain)". American Journal of Physical Anthropology 133 (3): 899-917.

Capaldo, S.D. 1998: "Methods, marks and models for inferring hominid and carnivore behaviour". Journal of Human Evolution 35: 323-326.

Castaños, P. 1991: "Estudio de los restos faunísticos de la Cueva del Moro (Olvena-Huesca)". Bolskan 10: 79-107.

Castaños, P. 2004: "Estudio Arqueozoológico de los Macromamíferos de la Cueva de Chaves (Olvena-Huesca)". Salduie 4: 125-171.

Cerrillo, E. 2005: "Los Barruecos y las primeras comunidades agrícolas del Tajo interior. Campañas de excavación 2001 y 2002". Actas del III Congreso del Neolítico en la Península Ibérica (Santander 2003). Publicaciones de la Universidad de Cantabria: 935-944. Santander.

Courty, M.A. 1984: "Formation et evolution des acumulations cendreuses. Approche micromorphologique". En Actes du VIII Colloque Interrégional sur le Néolithique. CREPA: 341-353. Clermont-Ferrand.

Clutton-Brock, J. y Hammond, N. 1994: "Hot dogs: Comestible Canids in Preclassic Maya Culture at
Cuello, Belize". Journal of Archaeological Science 21: 819-826.

Davis, S. 1989: Arqueología de los animales. Ediciones Bellaterra. Barcelona.

Deniz, E. y Payne, S. 1982: "Eruption and wear in the mandibular dentition as a guide to ageing Turkish Angora gotas". En B. Wilson, C. Grigson y S. Payne (eds.): Ageing and Sexing Animal Bones from Archaeological Sites. BAR British Series 109. Oxford: 155-207.

Driesch, Von Den A. 1976: A guide to the measurement of animal bones from archaeological sites. Harvard University. Cambridge.

Estremera, M.S. 2003: Primeros Agricultores y Ganaderos en la Meseta Norte: El Neolítico de la Cueva de La Vaquera (Torreiglesias, Segovia). Junta de Castilla y León. Zamora.

García-Moncó, C. 2008: “De Brennan a Bogart. Un mayor papel protagonista para el perro entre las primeras sociedades productoras de la Península Ibérica". IV Congreso del Neolítico Peninsular (Alicante 2007): 411-417. Alicante.

Gifford, D.; Isaac, G. y Nelson, C. 1980: "Evidence for Predation and Pastoralism at Prolongad Drift: a Pastoral Neolithic Site in Kenya". Azania 15: 57-108.

Grant, A. 1982: "The use tooth wear as guide to the age of domestic ungulates". En B. Wilson, C. Grigson y S. Payne (eds.): Ageing and Sexing Animal Bones from Archaeological Sites. BAR British Series 109. Oxford: 91-109.

Greenfield, H. y Arnold, E. 2008: “Absolute age and tooth eruption and wear sequences in sheep and goat: determining age-at-death in zooarchaeology using a modern control sample". Journal of Archaeological Science 35: 836-849.

Halstead, P. 1981: "Counting sheep in Neolithic and Bronze Age Greece”. En I. Hodder, G. Isaac y N. Hamond (eds.): Patterns of the past. Studies in Honour of David Clark. Cambridge University Press. Cambridge: 307-336.

Harcourt, R.A. y Kent, A. 1974: "The Dog in Prehistoric and Early Historic Britain". Journal of Archaeological Science 1: 151-1.

Jensen, P. 2004: Etología de los animales domésticos. Editorial Acribia. Zaragoza.

Jiménez, P. 1998: “ La neolitización de la cuenca alta del Tajo. Nuevas propuestas interpretativas para el Neolítico de la Meseta". Complutum 9: 27-47.

Jourdan, L. 1976: La faune du site gallo-romain et paléo-chrétien de la Bourse (Marseille). Editions du CNRS. París.

Karkanas, P. 2006: "Late Neolithic household activities in marginal areas: The micromorphological evidence from the Kouveleiki caves, Peloponnese, Greece". Journal of Archaeological Science 33: 1628-1641. 
Khazanov, A.M. 1984: Nomads and the outside the World. Cambridge University Press. Cambridge.

Kunst, M. y Rojo, M. 1999: "El Valle de Ambrona: un ejemplo de la primera colonización neolítica de las tierras del Interior Peninsular". Actas del II Congrès del Neolític a la Peninsula Ibèrica (Valencia 1999). Saguntum. Extra-2: 259-270.

Liesau, C. y Montero, S. 1999: "Vorbericht über die Tierknochenfunde aus Ambrona (Soria)". Madrider Mitteilungen 40: 66-71.

Liesau, C. 2005: "Arqueozoología del caballo en la antigua Iberia”. Gladius 25: 187-206.

López, P. y Molero, G. 1984: “Análisis de los restos vegetales, faunísticos y polínicos del yacimiento de la Sarsa (Bocairente-Valencia". Trabajos de Prehistoria 41: 305-312.

López-García, J.M.; Cuenca-Bescós, G. y Rosell, J. 2008: "Resultados del estudio de microvertebrados del neolítico de la Cueva de El Mirador (Ibeas de Juarros, Sierra de Atapuerca, Burgos)". En Actas del IV Congreso del Neolítico Peninsular (Alicante 2007): 338-344. Alicante.

Mazo, C. y Montes, L. 1992: "La transición Epipaleolítico-Neolítico antiguo en el Abrigo de El Pontet (Maella, Zaragoza)". En P. Utrilla (coord.): Aragón/Litoral mediterráneo. Intercambios culturales durante la Prehistoria. Institución Fernando el Católico. Zaragoza: 243-254.

Molist, M. 2005: "Les activitats productives (II): Les pràctiques ramaderes". En E. Giralt (ed.): Història Agrària dels Paisos Catalans. Edicions de la Universitat de Barcelona. Barcelona: 147-178.

Montoya, J.M. 1983: Pastoralismo Mediterráneo. Ministerio de Agricultura, Pesca y Alimentación. Madrid.

Morales, A. y Martín, S. 1995: "Los mamíferos de la Cueva de Nerja: Análisis de las cuadrículas NM-80 y NT-82". En M. Pellicer y A. Morales (eds.): Fauna de la Cueva de Nerja I. Salas de la Mina y de la Torca. Campañas 1980-82. Patronato de la Cueva de Nerja. Nerja: 59-101.

Morales, A. y Martín, S. 2003: "Informe sobre los restos de mamíferos recuperados en los niveles neolíticos de la Cueva de La Vaquera”. En M.S. Estremera (ed.): Primeros agricultores y ganaderos en la Meseta Norte: El Neolítico de la Cueva de La Vaquera (Torreiglesias, Segovia). Junta de Castilla y León. Zamora.

Moreno, M. 1999: "Ethnographic observations of transhumant husbandry practices in Spain and their applicability to the archaeological sample". En L. Bartosiewicz y H. Greenfield (eds.): Trashumant pastoralism in southern Europe. Recent Perspectives from Archaeology, History and Ethnology. Archaeolingua. Budapest: 159-177.

Morlan, R.E. 1980: Taphonomy and Archaeology in the Upper Pleistocene of Northern Yukon Territory: a glimpse of peopling of the New World. 94. Mercury Series. Ottawa.

Munsil, R. 1983: "The first known domestication of wolves in Central Europe". En J. Clutton-Brock y C. Grigson (eds.): Animals and Archaeology: 3. Early herders and their flocks. BAR International Series 202. Oxford: 23-25.

Munson, P.J. 2000: “Age-correlated Differential Destruction in Bones and its Effect on Archaeological Mortality Profiles of Domestic Sheep and Goats". Journal of Archaeological Science 27: 391-407.

Muñoz, I.K. 2001: “Hallazgos neolíticos de las Vegas de Aranjuez. Nuevos datos sobre el Neolítico del Interior Peninsular". Estudios de Prehistoria y Arqueología Madrileñas 11: 45-58.

Noddle, B. 1974: "Ages of Epiphyseal Closure in Feral and Domestic Goats and Ages of Dental Eruption". Journal of Archaeological Science 1: 195-204.

Oms, X.; Bargalló, A.; Chaler, M.; Fontanals, M.; García, M.S.; López-García, J.M.; Morales, J.I.; Nievas, T.; Rodríguez, A.; Serra, J.; Solé, A. y Vergès, J.M. 2008: "La Cova Colomera (Sant Esteve de la Sarga, Lleida), una cueva redil en el prepirineo de Lérida. Primeros resultados y perspectivas de futuro". En Actas del IV Congreso del Neolítico Peninsular (Alicante 2007): 230-236. Alicante.

Pales, L. y Lambert, P. 1970: Atlas d'Osteologie. Les membres. Editions du CNRS. París.

Payne, S. 1969: "A metrical distinction between sheep and goat metacarpals". En P.J. Ucko y G.W. Dimbley (eds.): The Domestication and Exploitation of Plants and Animals. Duckworth. Londres: 295-305.

Payne, S. 1973: "Kill-off patterns in sheep and goats: the mandibles from Asvan Kale". Anatolian Studies 23: 281-303.

Pellicer, M. y Morales, A. 1995: Fauna de la Cueva de Nerja I. Salas de la Mina y de la Torca, Campañas 1980-82. Patronato de la Cueva de Nerja. Nerja: 57-146.

Pérez Ripoll, M. 1980: "La fauna de vertebrados". En Martí, B. (ed.): Cova de L'Or (Beniarrés-Alicante) II. Diputación de Valencia. Valencia: 193-253.

Pérez Ripoll, M. 2006: "El estudio Arqueozoológico del Abric de La Falguera (Alcoi, Alacant)". En O. García y J. Aura (coords.): El Abric de la Fulgura (Alcoi, Alacant). 8000 años de ocupación humana en la cabecera del río Alcoy 2. Diputación Provincial de Alicante. Alicante: 120-157.

Perkins, D. y Daly, P. 1968: “A Hunter's Village in Neolithic Turkey". Scientific American 219 (5): 96-106.

Rodanés, J.M. y Ramón, N. 1995: “El Neolítico en Aragón: Hábitat y Territorio". Zephyrus XLVIII: 105-128. 
Rodríguez, X.P. 2004: Technical systems of lithic production in the Lower and Middle Pleistocene of the Iberian Peninsula: technological variability between north-eastern sites and the Sierra de Atapuerca sites. BAR International Series 1323. Oxford.

Rodríguez, A. y Buxó, R. 2008: “Cultivos y alimentación vegetal durante el Neolítico en la Cueva de El Mirador (Sierra de Atapuerca, Burgos)". En Actas del IV Congreso del Neolítico Peninsular (Alicante 2007): 317-325. Alicante.

Rojo-Guerra, M.A. y Kunst, M. 1996: "Proyecto de colaboración hispano-alemán en torno a la introducción de la neolitización en las tierras del interior peninsular. Planteamiento y primeros resultados". Cuadernos de Prehistoria y Arqueología de la Universidad Autónoma de Madrid 23: 87-113.

Rojo-Guerra, M.A.; Kunst, M.; Garrido, R. y García-Martínez, I. 2006: "La Neolitización de la Meseta Norte a la luz del C-14: análisis de 47 dataciones absolutas inéditas de dos yacimientos domésticos del Valle de Ambrona, Soria, España". Archivo de Prehistoria Levantina 26: 39-100.

Rowley-Conwy, P. 1998: "Improved Separation of Neolithic Medapodials of Sheep (Ovis) and Goats (Capra) from Arene Candide Cave, Liguria, Italy". Journal of Archaeological Science 25: 251-258.

Saña, M. 1998: "Arqueozoologia I faunes neolitiques a Catalunya. Problemàtica plantejada entorn a la dinàmica del procès de domesticació animal". Cypsela 12: 99-110.

Schmidt, E. 1972: Atlas of animal bones. For Prehistorians, Archaeologists and Quaternary Geologists. Elsevier Publishing Company. Amsterdam.

Shipman, P. y Rose, J. 1983: "Early Hominid Hunting, Butchering and Carcass-Processing Behaviors: Approaches to the Fossil Record". Journal of Anthropological Archaeology 2: 57-98.

Silver, I.A. 1969: "La determinación ósea de los animales domésticos". Ciencia en Arqueología. Fondo de Cultura Económica. México: 229-239.

Utrilla, P. 1996: "La explotación de los recursos: hábitat y territorio". Bolskan 13: 147-171.
Utrilla, P. y Baldellou, V. 1996: “Evolución diacrónica del doblamiento prehistórico en el valle del Cinca-Ésera. El registro de Olvena y otros yacimientos pirenaicos". Bolskan 13: 239-261.

Uerpmann, H.P. 1973: “Animal Bone Finds and Economic Archaeology. A Critical Study of OsteoArchaeological Method". World Archaeology 4 (3): 307-322.

Vergès, J.M.; Allué, E.; Angelucci, D.; Burjachs, F.; Carrancho, A.; Cebrià, A.; Expósito, I.; Fontanals, M.; Moral, S.; Rodríguez, A. y Vaquero, M. 2008: "Los niveles neolíticos de la Cueva de El Mirador (Sierra de Atapuerca, Burgos): nuevos datos sobre la implantación y el desarrollo de la economía agropecuaria en la submeseta norte". En Actas del IV Congreso del Neolítico Peninsular (Alicante 2007): 418-427. Alicante.

Vergès, J.M.; Allué, E.; Angelucci, D.; Cebrià, A.; Díez, C.; Fontanals, M.; Manyanós, A.; Montero, S.; Moral, S.; Vaquero, M. y Zaragoza, J. 2002: "La Sierra de Atapuerca durante el Holoceno: datos preliminaries sobre las ocupaciones de la Edad del Bronce en la Cueva de El Mirador (Ibeas de Juarros, Burgos)". Trabajos de Prehistoria 59 (1): 107-126.

Vigne, J.D. 1991: "The meat and offal weight (MOW) method and the relative proportion of ovicaprines in some ancient meat diets of the north-western Mediterranean". Revista di Studi Liguri 57 (1-4): 21-47.

Villa, J.R. y Mahieu, E. 1991: "Breakage patterns of human long bones". Journal of Human Evolution 21: 27-48.

Violant i Simorra, R. 1986: El Pirineo español. Vida, usos, costumbres, creencias y tradiciones de una cultura milenaria que desaparece. Alta Fulla. Barcelona.

White, T. 1992: Prehistoric Cannibalism at Mancos 5MTUMR-2346. Princeton University Press. Princeton. 